\title{
Uma abordagem centrada no usuário para o projeto de máquinas agrícolas de tração animal
}

\author{
An user centered approach to the design of animal traction \\ agricultural machinery
}

\section{Eduardo Romeiro Filho'}

\begin{abstract}
Resumo: Este artigo apresenta um estudo realizado como parte do projeto de uma semeadora-adubadora à tração animal, utilizando princípios relacionados a disciplinas como Usabilidade, Ergonomia e Antropotecnologia, dentro de uma perspectiva de Design para Sustentabilidade (DfS) e desenvolvimento de produtos adequados à Base da Pirâmide (BoP). O estudo forneceu subsídios para uma série de alterações a serem introduzidas no equipamento, tendo em vista a melhoria das condições de trabalho em pequenas propriedades de agricultura familiar. A partir desta abordagem na análise de um implemento existente, são sugeridas formas de adequação do produto e apresentada uma proposta para uma nova semeadora-adubadora à tração animal.
\end{abstract}

Palavras-chave: Ergonomia. Antropotecnologia. Semeadora-adubadora à tração animal. Projeto do produto. Design para sustentabilidade. Design para a base da pirâmide.

\begin{abstract}
This paper presents a study conducted as a part of the design of an Animal Traction Sewing Machine using principles related to Usability, Ergonomics, and Antropotechnology focusing on Design for Sustainability (DfS) and product development suitable for the Base of the Pyramid (BoP). The present study provided information for a series of design changes in the equipment in order to improve working conditions in small family farming properties. From this approach to the analysis of an existing implement, ways of adjusting the product are suggested, and a proposal for a novel Animal Traction Sowing Machine is presented.
\end{abstract}

Keywords: Ergonomics. Antropotechnology. Animal traction sowing machine. Product design. Design for sustainability. Design for the base of the pyramid.

\section{Introdução}

As máquinas agrícolas representaram importantes ferramentas, visto que a força humana ainda é a principal fonte de energia para o trabalho agrícola em países em desenvolvimento (JAFRY; O'NEILL, 2000) e responsável por aproximadamente metade da área cultivada no mundo (RAMASWAMY, 1994). No atual cenário brasileiro (e de outros países na América Latina, África e Ásia), diante da necessidade de criação de formas de desenvolvimento sustentável e geração de renda para a população mais pobre, a criação de empregos no campo por meio do incentivo à agricultura familiar é uma interessante alternativa. Nestes casos em que a pequena propriedade é uma característica mercante, a utilização de ferramentas de baixo custo e forte adequação tecnológica é essencial. A possibilidade de aplicação de recursos renováveis, dentre os quais a energia da tração animal, usada em diversas situações incompatíveis com máquinas de tração mecânica (além de representar um baixo investimento) deve ser também sempre considerada. Em meados dos anos 1990, animais de tração economizavam o equivalente a US\$ 6 bilhões em combustíveis fósseis, com mais de 300 milhões de animais utilizados (WILSON, 2003). Somente no México, por exemplo, são mais de 3.765.000 animais utilizados na agricultura (ORTIZ-LAUREL, RÖSSEL, 2007).

Entretanto, as ferramentas e implementos de tração animal disponíveis no mercado brasileiro caracterizam-se primordialmente por soluções tecnológicas e de projeto defasadas (DE ARAUJO; CASÃO JUNIOR; DE FIGUEIREDO, 1999), como no caso de semeadoras (Figura 1). Sendo assim, tendo em vista a necessidade de novas soluções adequadas ao pequeno produtor rural, deve-se compreender as necessidades e características bastante peculiares deste agricultor, que, na maior parte das vezes, não possui domínio sobre sistemas tecnológicos considerados avançados e apresenta restrições importantes em termos de condições temporais para o trabalho no campo. As indústrias brasileiras de máquinas agrícolas, no que pese sua importância para o País e seu potencial

\footnotetext{
Departamento de Engenharia de Produção - DEP, Laboratório Integrado de Design e Engenharia do Produto - LIDEP, Universidade Federal de Minas Gerais - UFMG, Av. Presidente Antônio Carlos, 6627, Campus da Pampulha, CEP 31270-901, Belo Horizonte, MG, Brasil, e-mail: romeiro@ufmg.br
} 
exportador, ainda carecem em sua maioria de um sistema de desenvolvimento do produto sistematizado (ROMANO et al., 2005), apresentando oportunidades para aplicação de novas ferramentas e abordagens de projeto. Em se tratando de bens de capital que muitas vezes envolvem investimentos relevantes por parte de seus compradores, a preocupação com padrões de eficiência que garantam o retorno financeiro em tempo adequado mostra-se fundamental. A esta preocupação deve-se unir um enfoque voltado para o usuário destes equipamentos, tendo em vista aspectos de segurança, conforto e eficácia, característicos de uma abordagem de ergonomia e design industrial.

A partir do exposto, este artigo tem por objetivo apresentar a contribuição ao projeto de uma semeadora-adubadora (de grãos) à tração animal a partir de uma abordagem que considere princípios de Usabilidade, Ergonomia e Antropotecnologia, com vistas à adequação do produto à agricultura sustentável e sua aplicação em pequenas propriedades, características da Base da Pirâmide (PRAHALAD,
2009). Este estudo foi desenvolvido a partir de um protótipo de um "chassi porta-implementos", construído pelo Instituto Agronômico de Campinas (Figura 2), e descrito por Peche Filho et al. (1987). O projeto do chassi porta-implementos foi desenvolvido pelo IAC com o objetivo de prover ao pequeno produtor um equipamento de baixo custo à tração animal (Figura 2). Partindo-se de uma base comum (o chassi), diferentes ferramentas poderiam ser acopladas, atendendo a diversas demandas existentes nos processos de cultivo, a partir de uma proposta de produto modular. Desta forma, foram desenvolvidas soluções para arados, cultivadores, gradeadores e, neste caso, uma semeadora adubadora, base para este estudo. O sistema técnico utilizado como base para o projeto da nova semeadora adubadora foi também desenvolvido pelo IAC (Figura 3).

A escolha pela semeadora-adubadora decorre do fato de esta apresentar uma série de problemas relacionados ao uso, como necessidades posturais advindas do peso do equipamento e da necessidade de
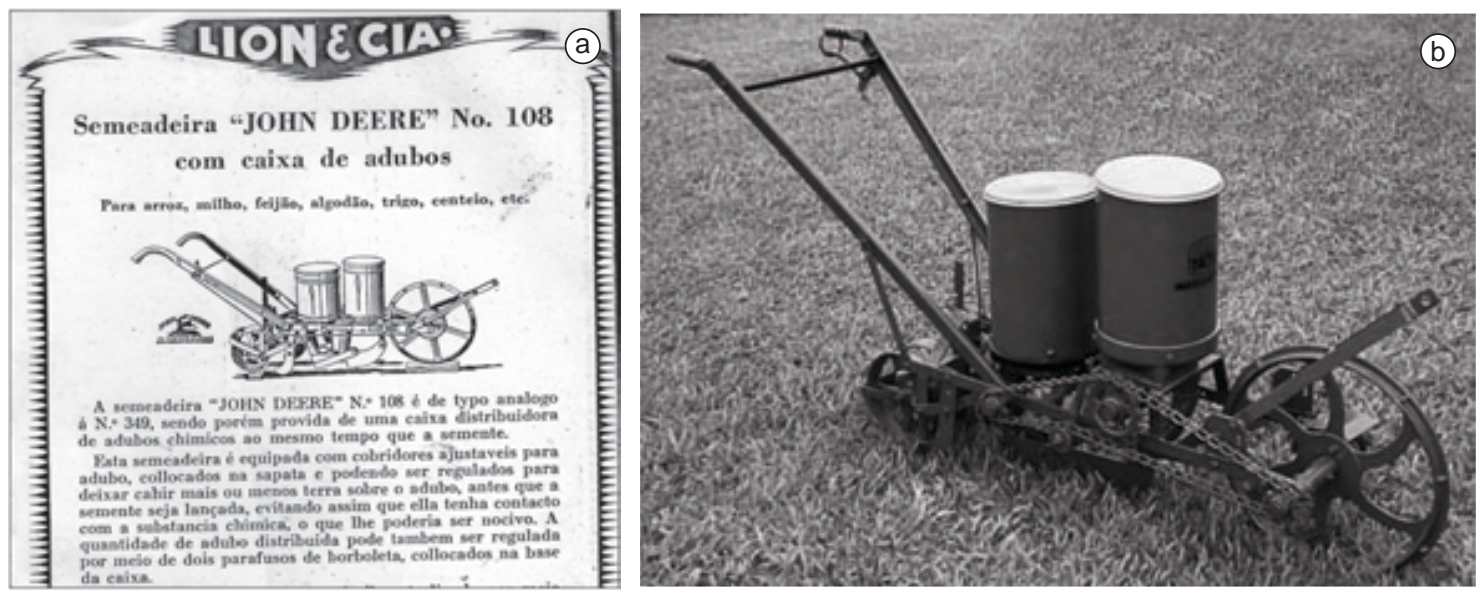

Figura 1. Exemplo de semeadora-adubadora produzida pela John Deere na década de 1920 (a), muito semelhante às disponíveis atualmente no mercado brasileiro (b). Fonte: arquivo do autor e http://www.marchesan.com.br.

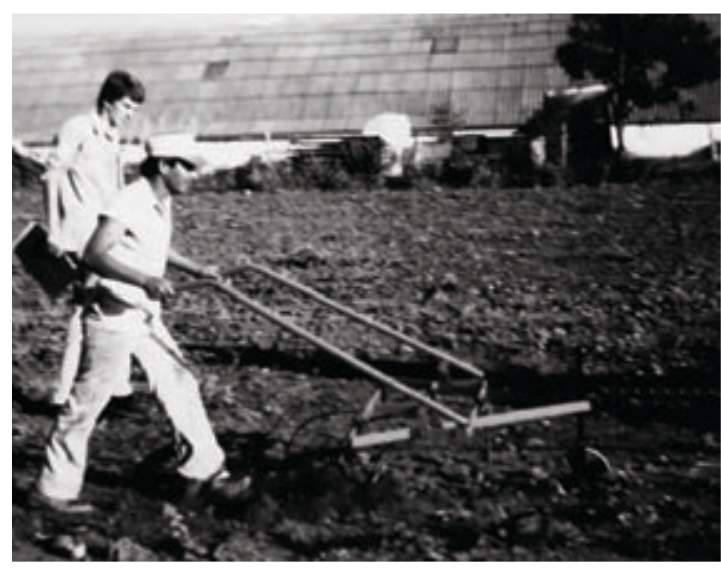

Figura 2. Protótipo do chassi porta-implementos, em estudos de campo.

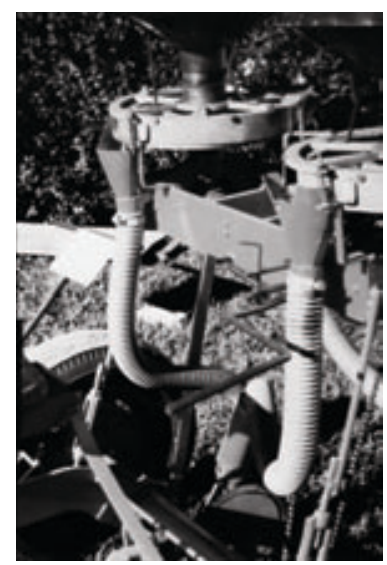

Figura 3. Protótipo de semeadora-adubadora à tração mecânica. Ambos desenvolvidos pelo IAC - Instituto Agronômico de Campinas. Fonte: arquivo do autor. 
equilíbrio durante o movimento (os depósitos elevam o centro de gravidade da máquina), além da constante tomada de informação, seja na condução do animal, nas condições do terreno, na velocidade e direção da trajetória, bem como no funcionamento do sistema de alimentação e saída de sementes e adubo. Por fim, foi determinante para a escolha o fato de tratar-se de um equipamento destinado ao pequeno produtor rural, que possui normalmente menor capacidade de investimento, seja em equipamentos como em novos sistemas de cultivo. Além disso, a modernização de equipamentos à tração animal pode contribuir positivamente para o desenvolvimento em extensas regiões ainda carentes em diversas partes do mundo.

\section{Demanda por melhores interfaces produto-usuário}

Embora o termo UCD tenha maior aplicação no campo de engenharia de software, nos estudos da interface homem-computador (NIELSEN, 1993), seus princípios podem ser aplicados a qualquer equipamento ou produto, pelo reconhecimento da importância dos usuários, suas necessidades, capacidades e limitações, e dos contextos em que estes se relacionarão com o produto. Importante também, como salienta Rubin (1994), ter-se em conta que UCD não representa apenas técnicas, métodos, processos e procedimentos para projetar produtos e sistemas "usáveis", mas, principalmente, a filosofia que coloca o usuário como centro do processo de projeto. Neste aspecto, Ergonomia e Usabilidade podem ser consideradas conceitos importantes em uma visão de UCD. Adler e Winograd (1992) definem usabilidade como a habilidade de um produto ou equipamento tirar vantagem das competências de seus usuários, funcionando de forma eficaz em uma dada gama de situações reais de trabalho. Neste sentido, o conceito aproxima-se dos princípios adotados em ergonomia. Desta forma, acredita-se que, embora não possam ser consideradas como disciplinas semelhantes (a exemplo da discussão acerca das diferenças entre ergonomia e fatores humanos), ambas podem ser incorporadas a uma perspectiva de projeto que traga como preocupação central o usuário em situação real de atividade com o produto. Também são considerados relevantes neste trabalho fatores ligados à Antropotecnologia (WISNER, 1985), visando avaliar os impactos resultantes da transferência de tecnologia entre regiões distintas, seja por suas características geográficas como também econômicas, sociais e culturais. No caso do trabalho agrícola, este aspecto é ainda mais importante, tendo em vista as diferenças de formação, tradição, condições de uso e conhecimento técnico entre agricultores. A solução técnica (ou conjunto de soluções) a ser adotada deve considerar estes fatores em seu desenvolvimento, a partir de uma abordagem "Antropotecnológica".

Atualmente, dentre os vários campos dedicados ao aperfeiçoamento da interface produto-usuário, a Usabilidade é talvez uma das mais utilizadas e que podem proporcionar resultados neste sentido. Nielsen (1993) afirma que é possível que qualquer objeto, produto, sistema, ou serviço que seja utilizado por seres humanos possua potenciais problemas em seu uso, e que estes deveriam ser submetidos a alguma forma de "Engenharia de Usabilidade". Apesar de terem sido observadas na revisão de literatura mais referências a respeito de estudos relacionados à interface produtousuário para o desenvolvimento de software, foram levantados estudos dedicados a equipamentos, bens duráveis e de capital, tais como equipamentos para transmissão de energia (COSTA, 2006), máquinas de usinagem CNC (SHINNO, 2002), aparafusadeiras elétricas (FREUND; TAKALA; TOIVONEN, 2000) e principalmente equipamentos médicos (ROSE et al., 2005, GARMER et al., 2002, CARROL et al., 2002, GARMER; YLVÉN; KARLSSON, 2004, LIU; OSVALDER, 2004). A literatura sugere que, apesar dos operadores destes equipamentos receberem treinamento, a aplicação de métodos para melhorar a usabilidade destes produtos é pertinente e benéfica ao projeto destes e aos seus usuários.

Neste caso, a aplicação de princípios da Ergonomia no desenvolvimento de soluções técnicas é especialmente recomendada, seja em uma abordagem voltada ao dimensionamento humano (DREYFUSS, 2001), aos aspectos fisiológicos do trabalho (KROEMER; GRADJEAN, 2005; IIDA, 2005) ou Fatores Humanos (NEMETH, 2004). Também metodologias de caráter participativo são citadas como úteis ao desenvolvimento de soluções adequadas ao ambiente rural (KOGI, 2006), em especial em países pouco desenvolvidos industrialmente (JAFRY; O’NEILL, 2000). A ergonomia também oferece oportunidades interessantes como contribuição ao desenvolvimento de equipamentos agrícolas a partir da aplicação da AET - Análise Ergonômica do Trabalho (descrita por GUÉRIN et al., 2001; WISNER, 1987). Embora o agricultor seja (na situação avaliada) proprietário dos meios de produção, ainda assim as formas de organização do trabalho (em especial aquelas relacionadas ao "tempo ótimo" para plantio) são reguladas por fatores que fogem a seu controle, de forma muito mais evidente do que no trabalho realizado em fábricas, por exemplo.

Além disso, é natural que tecnologias (bem como estruturas organizacionais) de determinados países não sejam facilmente adaptáveis a outros, conforme Wisner $(1985,1987,1991)$, em seus estudos relacionados à Antropotecnologia. Shahnavaz (1991) inclui nesta avaliação uma abordagem mais ligada a Fatores Humanos ("Human Factors") e 
a impactos da transferência de tecnologia entre países de diferentes níveis de desenvolvimento. Várias experiências demonstram que tecnologias concebidas em determinada realidade, ao serem transferidas para outra, em um contexto distinto, devem sofrer modificações significativas, com o intuito de adaptá-las às condições peculiares à região a que se destinam e à sua população. Populações com culturas e tradições próprias, diferentes níveis de educação formal, conhecimento tecnológico e formas de produção requerem soluções técnicas peculiares. Este problema é ainda mais grave na agricultura, na qual fatores climáticos, geográficos e de cultivares influenciam diretamente a adequação (ou não) de tecnologias importadas. Dentro de um mesmo país podem existir grandes diferenças regionais que devem ser consideradas na concepção, planejamento e implantação de tecnologias, aspecto particularmente importante no Brasil. A questão, nestes casos, reside na investigação sobre a real situação do trabalho rural, incluindo variáveis normalmente não previstas pelos projetistas, como situações de "utilização degradada" ou restrições de manutenção comuns em situações de campo. A abordagem voltada para o usuário busca contribuir, desta forma, na investigação de situações reais de utilização do equipamento, fornecendo novos elementos para a equipe de projeto.

\section{A tração animal}

A energia animal foi adotada como parâmetro neste estudo por ser de grande importância para o desenvolvimento da agricultura, principalmente nas pequenas e médias propriedades, em regiões pioneiras ou em condições desfavoráveis de topografia. Isto indica que há grande potencial para a utilização desta forma de energia, sendo este um segmento pouco atendido pelas fábricas de implementos, mais voltadas no desenvolvimento de equipamentos adequados à utilização em grandes propriedades. Apesar de restrições de ordem econômica e técnica ao aproveitamento da energia animal, esta apresenta vantagens relevantes, que merecem ser analisadas: trata-se de fonte de energia abundante, renovável, descentralizada e móvel, que não depende de insumos (como combustíveis) ou equipamentos importados que ocasionem dependência externa. $\mathrm{O}$ custo do investimento é baixo, se comparado com alternativas tecnológicas como o trator mecânico, que não é acessível à maioria dos agricultores em pequenas propriedades em diferentes regiões do mundo. Além disso, ela se presta ao uso em regiões de topografia acidentada para a qual a mecanização não é apropriada. Também a geração de empregos, em confronto com a moto-mecanização, é muito maior, sendo este um fator importante a se considerar onde há grande disponibilidade de mão de obra e a necessidade de geração de renda. Por fim, a utilização da tração animal como fonte de energia em estabelecimentos servidos apenas pela força humana representa sem dúvida um substancial progresso tecnológico e grandes ganhos em produtividade. Além disso, há uma inegável melhoria nas condições de trabalho do agricultor a partir da utilização deste tipo de tração, visto que grande parte do esforço físico é transferida para o animal.

\section{A metodologia de pesquisa}

A primeira fase da pesquisa foi realizada a partir de observações livres (não sistemáticas), etapa do método de AET (GUÉRIN et al., 2001). Estas observações demonstraram que as variáveis relevantes à compreensão da atividade eram o deslocamento, postura, tomada de informação e direção do olhar, o que foi verificado em observações detalhadas. De fato, as observações posteriores, bem como referências consultadas (SANTOS, 1986) demonstraram que o acompanhamento do fluxo de sementes e adubo é essencial à realização satisfatória da tarefa proposta. Sendo assim, definiu-se que a localização mais adequada para o condutor seria atrás do mecanismo da semeadora, em tal situação que fosse possível o acompanhamento constante do funcionamento da máquina.

Para a concepção da nova semeadora a partir de uma abordagem centrada no usuário, foram realizadas diversas observações em campo (Figura 2) com o uso do chassi em outras aplicações (como cultivadores de mola), ao longo de aproximadamente um mês, uma vez que o protótipo da semeadora não havia sido construído. Além disso, foram levantadas as principais características (técnicas e dimensionais) de algumas das semeadoras à tração animal disponíveis no mercado brasileiro, tendo sido também acompanhado o uso de um destes modelos em situação de plantio.

Tendo em vista o fato de que as condições de uso de semeadoras apresentam características muito distintas daquelas observadas em outras etapas do processo de cultivo, foi realizada também uma revisão de literatura sobre o tema, levantando especialmente as necessidades posturais e de tomada de informação no uso de equipamentos agrícolas. Este aspecto foi especialmente importante, tendo em vista o fato de que o projeto foi conduzido a partir da adaptação de um sistema técnico originalmente desenvolvido para tração mecânica (Figura 3) para a tração animal. Foi construído um protótipo da semeadora, mas somente para a avaliação do funcionamento do sistema técnico proposto (Figura 4).

A ergonomia (em especial a AET) pressupõe uma análise detalhada da atividade em situação real, realizada a partir das observações de campo. Entretanto, não existia uma situação anterior de uso de semeadora em semelhante chassi, mais largo do que outros modelos existentes no mercado. Com 
efeito, o projeto previa a utilização da semeadora em duas linhas, o que tornava a máquina mais estável do que outras existentes, que funcionam em apensa uma linha. Não foi identificada, na pesquisa de similares no mercado, nenhuma semeadora com tais características. A intervenção configura-se, desta forma, em uma abordagem situada entre aquelas denominadas por Iida (2005) como "ergonomia de correção" (visto que tratava da adequação do chassi existente) e "ergonomia de concepção" (visto que a semeadora apresentou diversos aspectos inéditos em relação às demais existentes no mercado).

Neste caso, a abordagem ergonômica foi complementada por algumas ferramentas adaptadas a partir das descritas nas normas ISO/TR 13407: Human-Centred Design Process for Interactive Systems (INTERNATIONAL.., 1999), e ISO/TR 18529 (INTERNATIONAL..., 2000): Observação de usuários; Questionários; Entrevistas; e Avaliação de Perito. A forma de aplicação de questionários, em especial, diferiu das entrevistas e verbalizações previstas na AET. Foram dirigidas a pesquisadores (neste caso considerados "peritos") e buscavam abordar aspectos técnicos relacionados à utilização do equipamento, como, por exemplo, a compatibilidade de diferentes sistemas de plantio à utilização de determinado sistema de sulcagem de solo, o que acabava por interferir com o esforço demandado e com o período "ótimo" para plantio. Desta forma, foi possível a construção de uma base de informações que serviu à construção da situação a ser abordada no projeto em vários aspectos.

Como elemento essencial para a complementação da abordagem, foi utilizada uma revisão de literatura acerca das implicações da transferência de tecnologia entre realidades distintas, para que a antropotecnologia fosse incorporada como "filosofia de projeto" ao processo de concepção da solução técnica. Este aspecto revelou-se especialmente importante, pois ressaltou a importância da adequação da solução final às diferentes realidades encontradas no campo brasileiro como elemento essencial à aceitação do produto pelos usuários finais. Neste caso, mais uma vez a utilização de questionários enviados aos pesquisadores mostrou-se pertinente ao desenvolvimento da nova máquina.

Por fim, para o dimensionamento dos comandos da máquina e determinação de ângulos de visão necessários ao alcance das informações necessárias à atividade de trabalho, foram utilizadas tabelas antropométricas disponíveis, como Dreyfuss (2001) e Ferreira (1988).

\section{A semeadora-adubadora}

Para o desenvolvimento da semeadora-adubadora de tração animal, parte-se do princípio de que é imprescindível considerar as reais necessidades da população usuária e os dados geográficos, climáticos, demográficos, culturais e sociológicos de cada região, sob pena de não se conseguir de forma adequada a transferência e difusão da nova solução, principalmente em se tratando de tecnologias ligadas ao meio rural, tradicionalmente mais conservador. Neste caso específico, em se tratando da implantação de equipamentos agrícolas à tração animal em diversas regiões do Brasil, convém considerar que:

- A existência de diversos níveis de competência entre uma população e outra (alguns trabalhadores mais familiarizados que outros com aspectos mecânicos, alguns analfabetos, alguns mais habilitados ao adestramento de diferentes espécies animais) pode implicar no planejamento de processos de formação diferenciados, de forma a atender satisfatoriamente aos vários grupos;

- As diferenças geográficas, os diferentes tipos de solo, as características do terreno, podem fazer com que alguns equipamentos sejam bem mais aceitos e tenham um melhor desempenho em uma região que em outra.

As diferenças climáticas podem implicar em uma organização de trabalho específica (número de pausas, repouso) para cada situação. Em regiões onde o trabalhador é exposto a temperaturas mais elevadas, os equipamentos mais pesados e/ou que impliquem num maior dispêndio físico por parte do agricultor podem apresentar maiores inconvenientes em relação à sua aceitação pelos usuários;

- As diferenças demográficas (disponibilidade de mão de obra), os meios de comunicação existentes, o acesso aos programas de formação podem exigir uma dupla de operadores para conduzir o equipamento e os animais ao invés de uma única pessoa. Além disso, o animal (ou animais) utilizado pode requerer uma segunda pessoa para direção deste animal.

Além destes, outros fatores que influenciam no aumento dos custos do trabalho com a tração animal (SANTOS, 1986):

- O clima;

- As restrições temporais (prazos de execução de trabalhos em função da condição ótima do ambiente físico, períodos de ponta);

- Os esforços físicos demandados pelo equipamento, bem como as posturas necessárias para captar informações;

- O animal utilizado (e consequentemente a velocidade e força de tração) e condições de marcha que demandam maiores esforços físicos por parte do operador (ex. terreno arcado, com pedras, etc.); 
- As difíceis manobras impostas ao final das linhas por certos equipamentos e pela utilização de juntas de animais;

- A experiência e competência dos operadores (durante a fase de aprendizagem de operação da nova máquina ele poderá ter um dispêndio energético maior).

\subsection{A questão da fadiga}

A fadiga pode ser considerada como uma diminuição reversível da capacidade funcional de um órgão ou de um organismo em consequência de uma atividade (IIDA, 2005). Ela pode ser normalmente recuperada após um período de pausa ou descanso. $\mathrm{O}$ conceito de fadiga inclui tanto a redução objetiva da capacidade dos mecanismos neuromusculares, quanto os sentimentos subjetivos de desconforto e cansaço. No caso do trabalhador rural, quando este utiliza a semeadora de tração animal, a fadiga provém principalmente de determinados fatores, apontados a seguir:

- Esforço de estabilização da máquina, pois as semeadoras convencionais, de apenas uma linha, são bastante altas, o que as torna muito instáveis. Mesmo estando paradas, é muitas vezes difícil mantê-las de pé. Este é um item que requer esforço e atenção constantes por parte do operador, sob o risco de tombamento da máquina;

- Realização de manobras ao final de cada linha de plantio. A máquina deve ter sua parte traseira levantada e girar $180^{\circ}$ sobre a roda dianteira. Quando há utilização de uma junta de bois este trabalho é ainda mais difícil, dadas as características específicas destes animais. Se for levado em consideração o peso destas máquinas, que chega a setenta quilos estando vazias, ter-se-á uma ideia do esforço despendido;

- Levantamento da máquina para retirada da palha do dispositivo de plantio, quando há embuchamento;

- Correções da trajetória da máquina com a estabilização. O operador tem que estar atento também à trajetória assumida pela máquina, tendo que realizar constantemente correções, visando manter a qualidade do trabalho e o paralelismo das linhas de plantio;

- Abastecimento dos depósitos de semente e fertilizante, realizado várias vezes por hectare, de acordo com o tamanho das sementes e/ou densidade do plantio. $\mathrm{O}$ agricultor leva para o campo vários sacos de sementes, deixando-os em pontos estratégicos para o reabastecimento da máquina no momento adequado;

\subsection{O aspecto postural}

Em termos de avaliação da atividade, a postura assume uma importância central, pois é uma variável facilmente observável (GUÉRIN et al., 2001) e relacionada diretamente às necessidades da atividade, como aplicação de forças e tomada de informações relevantes ao desenvolvimento do trabalho. Pheasant e Harris (1982 apud IIDA, 2005) analisam as mudanças ocorridas após a aplicação de sistemas de tração mecânicos na agricultura. A inversão da posição do agricultor (colocado agora à frente do implemento) leva à necessidade de contínua torção do tronco, de maneira a acompanhar a evolução do cultivo pelo implemento puxado pelo trator. Trata-se de uma clara inadequação, visto que a ação do implemento no solo é uma fundamental fonte de tomada de informação para que a tarefa seja conduzida de forma adequada. Curiosamente, mesmo em anúncios antigos, datados do início do século passado, as semeadoras em duas ou mais linhas à tração animal previam o agricultor sentado sobre o equipamento.

A partir da AET com a semeadora-adubadora, pode-se perceber que as posturas assumidas durante $\mathrm{o}$ trabalho de semeadura denotam a grande importância do controle, pelo operador, da saída de sementes do depósito. Como consequência da exploração visual necessária à execução da semeadura, o operador da semeadora-adubadora (posicionado atrás do implemento) assume uma postura inclinada para frente durante mais de $50 \%$ do tempo de trabalho. Com a observação, verificou-se que o operador controla de maneira contínua a saída de sementes e que a cada dez minutos, em média, verifica o nível de sementes no depósito. Outro dado importante no que se refere à postura é a posição das rabiças (instrumentos de pega do operador nos implementos à tração animal), nem sempre em regulagens que permitam altura e/ou largura adequadas. Seu melhor dimensionamento poderia reduzir bastante os custos posturais do operador.

\section{Recomendações para melhoria no equipamento}

Uma melhoria dos equipamentos se faz necessária, portanto, de maneira a aumentar seu desempenho, e ao mesmo tempo propiciar aos usuários melhores condições de trabalho. Deve-se prever sempre que possível que o usuário trabalhe em postura adequada, sem a necessidade de esforço exagerado e com boas condições de visibilidade para controle de seu sistema à tração animal. Cabe ainda aos novos projetos de equipamentos agrícolas à tração animal: 
- Melhorar o desenho da barra de tração do implemento, de forma que este possa "pivotar" e facilitar as manobras, grandes fontes de dispêndio energético;

- Simplificar e aprimorar os sistemas de regulagem da máquina, de maneira que a manutenção seja realizada de forma mais rápida e eficiente;

- Priorizar e facilitar o acesso às formas de informação necessárias à elaboração de suas estratégias de ação (por exemplo, área de saída de sementes). Nestes casos, a avaliação do operador sobre os resultados alcançados pelo equipamento é essencial ao desenvolvimento da atividade;

- Evitar o trabalho nas horas mais quentes do dia, seja por meio de formas de organização do trabalho como pela adoção de cultivares (ou variedades) que permitam um período de plantio mais longo;

- Informar aos agricultores não somente a lógica de utilização das máquinas, mas também a lógica de seu funcionamento mecânico, capacitando-os a diagnosticar defeitos e efetuar pequenos reparos do material em campo;

- Desenvolver implementos a partir de elementos incorporados pelo agricultor, de seu "saber fazer", de maneira que estes possam ser mais bem adaptados e mais aceitos pelos agricultores;

- Desenvolver soluções técnicas alternativas de maneira a atender a diferentes demandas apresentadas por usuários distintos. Neste caso, a concepção de uma base comum (o chassi) permite uma forma de "projeto modular",

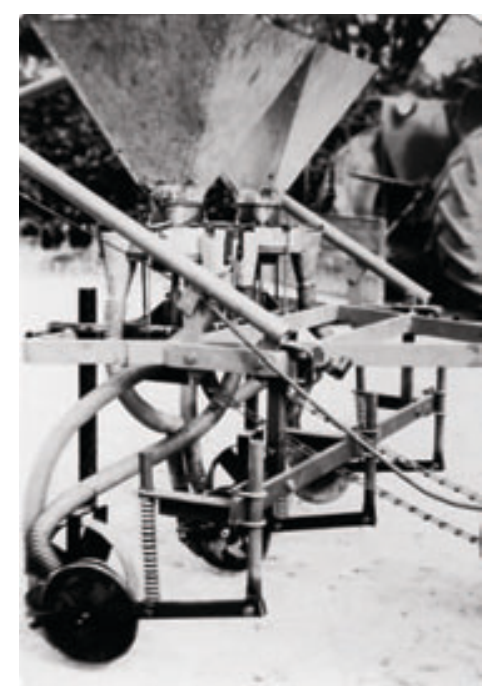

Figura 4. Protótipo da semeadora adubadora construído pelo IAC, acoplado ao chassi porta-implementos. reduzindo os custos de produção e difusão de equipamentos amplamente adaptados às diferenças regionais ou mesmo às características de cada agricultor;

- Capacitar os fornecedores dos equipamentos, sejam empresas privadas ou públicas (como serviços de extensão rural), no diagnóstico da solução técnica (e dimensional) mais adequada a cada agricultor, com base no conceito de modularidade dos implementos acoplados ao chassi;

- Divulgar novas técnicas agrícolas aos produtores, de forma que estes tenham maior quantidade de opções para elaboração de seu trabalho, utilizando cultivares ou variedades que permitam, por exemplo, uma época de plantio mais longa;

- Difundir manuais de operação das máquinas aos operadores (estes devem ser adequados de maneira a atender de maneira satisfatória mesmo os analfabetos).

No caso do projeto proposto, a partir do sistema técnico de semeadura inicialmente previsto para uso com tração mecânica, foi construída uma versão mais leve e compacta, a ser acoplada no chassi original (Figura 4). Não foi construído, por outro lado, um protótipo com as características propostas a partir do estudo para testes de campo em situação real. Em se lugar, foi construída uma maquete com as alterações propostas (Figura 5). Embora seja uma limitação para a avaliação dos resultados do estudo, podem ser observadas alterações interessantes no projeto, no sentido de tornar o equipamento mais adequado às situações reais de trabalho no campo, considerando os diferentes componentes da carga de trabalho (WISNER, 1987).

Como exemplo para a redução do componente físico da carga de trabalho, chama-se a atenção (Figura 6) para o dimensionamento e curvatura das

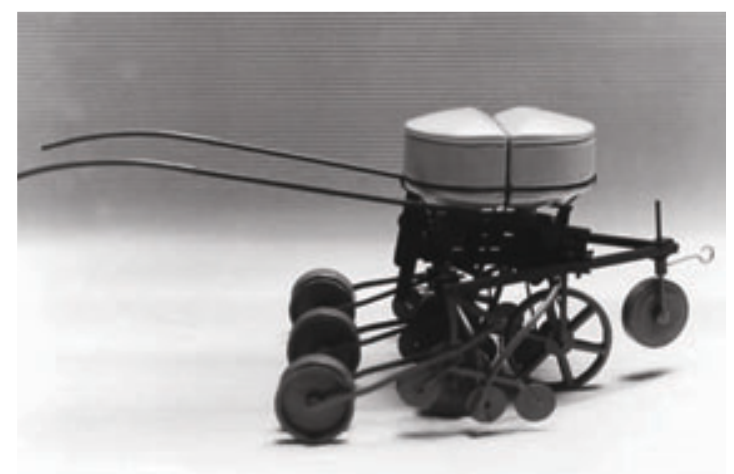

Figura 5. Maquete do equipamento após as alterações propostas. Fonte: arquivo do autor. 


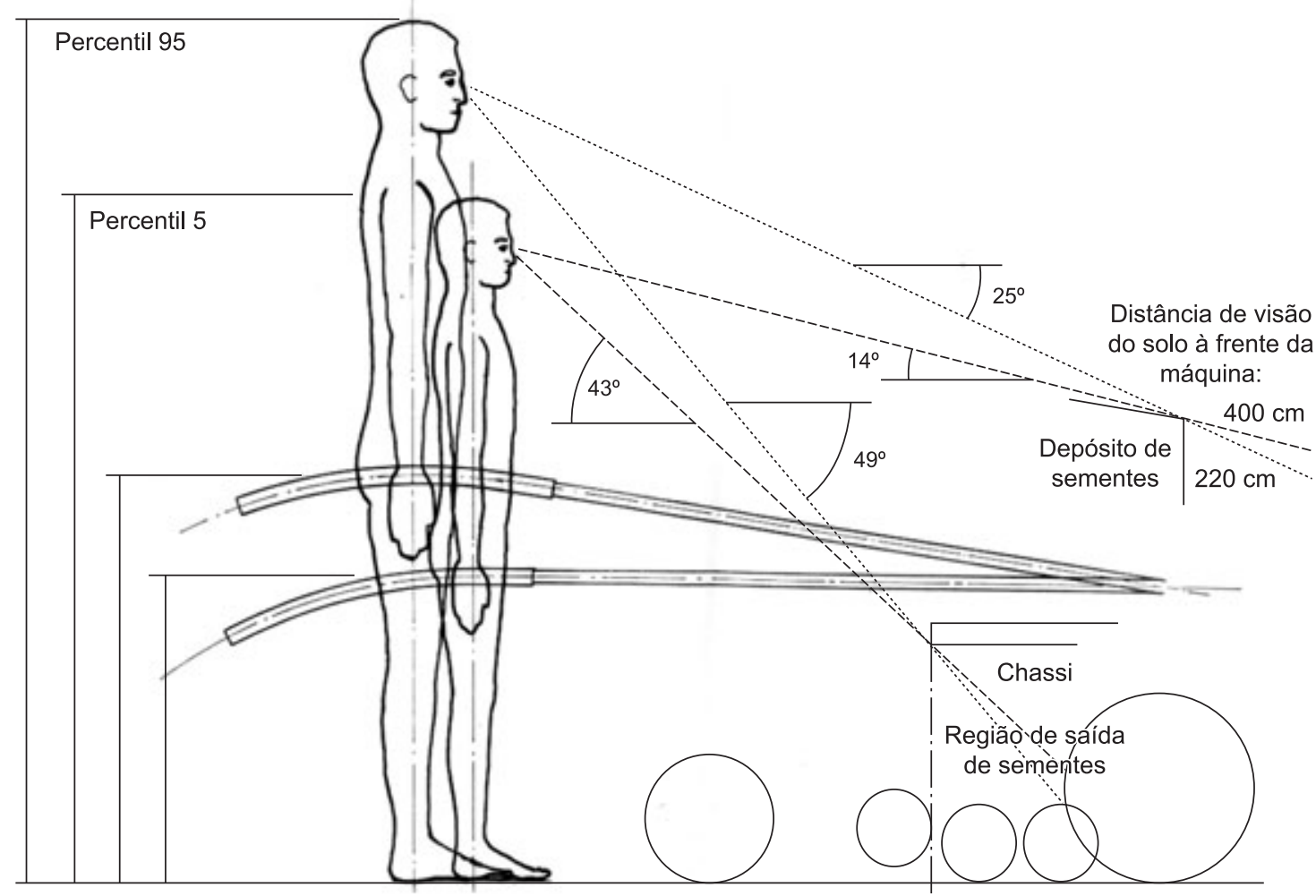

Figura 6. Desenho esquemático do resultado da aplicação de alguns princípios de dimensionamento a partir dos percentis 5 e $95 \%$. Dimensões definidas a partir de Dreyfuss (2001) e Ferreira (1988).

rabiças, visando uma empunhadura confortável em situações extremas. Foram propostas rabiças mais longas do que as tradicionais, que permitem maior facilidade nas manobras e mudanças de direção do equipamento. A utilização de duas ou até três linhas de plantio dá também maior estabilidade ao equipamento, diminuindo ainda mais os esforços do usuário. As rabiças mais longas permitem também uma melhor e contínua fiscalização do trabalho executado, sem maiores esforços posturais. O diâmetro adotado para empunhadura foi de $25 \mathrm{~mm}$ (definidos a partir de DREYFUSS, 2001), considerando-se a utilização de cobertura emborrachada.

Um aspecto importante para o componente cognitivo do trabalho é que o agricultor tenha acesso contínuo às informações de funcionamento da máquina, como fluxo de sementes, funcionamento de mecanismos e condições de execução do plantio. Foram consideradas as tomadas de informação da área de saída das sementes e distância de visão do solo à frente da máquina, tendo em vista altura total do depósito de sementes. Neste caso específico, foi levantada uma questão importante, pois a visão à frente da máquina é reduzida à medida que a estatura do condutor decresce. Por outro lado, deve-se considerar a existência do animal de tração, o que traria de qualquer forma a impossibilidade de visão do terreno à frente da máquina. Optou-se por manter o usuário em sua postura tradicional de trabalho, em pé e atrás da semeadora ainda que isso possa levar a um maior dispêndio físico. Por outro lado, esta decisão pode ser justificada pela pequena área de cultivo prevista para situações de uso da máquina.

Por fim, aspectos mecânicos do implemento também devem ser observados para uma maior adequação ao usuário. A utilização de sistemas de plantio menos vulneráveis ao embuchamento (acumulo de palha e restos de cultura no sistema de plantio) facilita a operação de plantio e diminui o esforço do operador, reduzindo a necessidade de limpeza da máquina, encurtando o tempo e facilitando todo o processo de plantio, o que acaba por trazer benefícios sobre a carga de trabalho. Além disso, a adoção de sistemas mecânicos simples permite maior facilidade para difusão do implemento, visto que um maior número de agricultores poderá compreendê-lo e utilizá-lo sem maiores dificuldades.

\section{Conclusões}

Tendo por base a revisão de literatura e as observações realizadas durante a pesquisa de campo, bem como em entrevistas junto a técnicos e agricultores, um conjunto de sugestões para melhoria de um modelo de semeadora-adubadora de tração animal foi apresentado. Este visa atender ao maior número possível de recomendações para satisfação das necessidades do usuário e minimização de sua considerável carga de trabalho. Neste caso, as conclusões deste trabalho indicam que existem 
inúmeras oportunidades de melhoria nos equipamentos agrícolas existentes no mercado, em especial em se tratando de implementos destinados aos pequenos proprietários rurais.

Durante muito tempo, tendo em vista um maior retorno financeiro e as próprias políticas de incentivo governamental, as empresas fabricantes concentraram esforços no desenvolvimento de implementos destinados a grandes propriedades rurais, fazendo com que a tecnologia destinada ao pequeno produto permanecesse "estagnada". Demonstra-se, portanto, a oportunidade para melhoria destes equipamentos. Entretanto, procurou-se enfatizar neste trabalho que as diferenças culturais, sociais, geográficas e econômicas existentes entre as diferentes regiões do País, além da diversidade climática e de cultivares, levam à necessidade de desenvolvimento de soluções técnicas de características bastante peculiares, de forma a atender satisfatoriamente às condições existentes.

Por outro lado, ressalta-se que este trabalho esteve centrado na apresentação de oportunidades de aplicação de princípios de UCD no projeto de uma máquina agrícola, e não no aprimoramento de sistemas mecânicos de plantio. Este é um desafio que depende também de outras ferramentas de projeto do produto, como, por exemplo, formas de projeto para modularidade. A partir de um chassi básico, podem ser desenvolvidas inúmeras soluções técnicas e de usabilidade, que podem ser adequadas às diferentes condições observadas, bem como às diferentes características dos usuários. Utilizando-se um sistema de produto modular, os custos de produção e aquisição seriam reduzidos, enquanto os serviços de extensão rural poderiam ser os responsáveis pela orientação aos agricultores sobre as melhores opções disponíveis em cada situação. Seria assim possível a construção de soluções adequadas às diferenças regionais em termos de clima, terreno, necessidades de cultura e mesmo com relação às distintas características dos usuários.

No caso apresentado, a escolha de uma máquina à tração animal decorre principalmente de um maior número de variáveis envolvidas, visto que os profissionais envolvidos com máquinas de tração mecânica normalmente possuem (ou deveriam possuir) formação específica para a tarefa. Desta forma, acredita-se que, no caso da tração animal, exista maior relevância dos saberes tradicionais, não formais, ligados à experiência do agricultor. Este aspecto acabou por tornar a pesquisa mais ampla e rica em seus resultados. Naturalmente os princípios de UCD podem e devem ser aplicados ao desenvolvimento de qualquer solução técnica ligada à atividade rural, seja em pequenas propriedades com fortes restrições técnicas e/ou financeiras como em grandes empreendimentos.

Ressalta-se que a principal contribuição do estudo apresentado concentra-se em uma abordagem teórica sobre o problema, bem como a proposição de uma série de recomendações baseadas em: 1) revisão de literatura, e 2) observações do uso de outros implementos em campo, que contribuíram para a elaboração de uma solução técnica que incorporasse as características de adequação aos usuários propostos, bem como atendesse às condições observadas em campo. Entretanto, não foi possível a construção de um protótipo completo da semeadora a partir das sugestões de melhoria, o que não permite uma comparação dos resultados alcançados em termos de, por exemplo, redução do tempo ou do esforço físico requerido para as diversas operações de plantio, ou avaliações de natureza mais qualitativa, como a percepção do conforto pelos usuários em situação real de uso da máquina em comparação com outros implementos de função similar.

É importante observar que a abordagem utilizada e os resultados propostos demonstram ser adequados para o desenvolvimento de implementos agrícolas destinados a pequenos produtores rurais. São, portanto, vários os aspectos que devem ser analisados diante de um projeto ligado ao meio agrícola, a partir de uma abordagem centrada no usuário. Esta deve considerar aspectos específicos do trabalho e da vida rural, que apresentam grandes diferenças em relação ao ambiente de trabalho urbano, que é normalmente objeto de estudo pela ergonomia. O número de variáveis aplicadas ao trabalho rural, ligadas a fatores climáticos, geográficos e de cultivares, por exemplo, torna mais complexa a análise, demandando estratégias e ferramentas metodológicas específicas na busca de soluções técnicas que atendam às necessidades do setor. A aplicação desta abordagem no projeto de máquinas agrícolas pode contribuir para a solução de diversas demandas do campo e na melhoria das condições de trabalho e de vida da população rural.

\section{Agradecimentos}

$\mathrm{O}$ autor agradece à equipe da Seção de Máquinas de Colheita e Processamento de Produtos Agrícolas da Divisão de Engenharia Agrícola do Instituto Agronômico de Campinas, por meio do Dr. Claudio Alves Moreira, sem a qual seria impossível a realização deste trabalho. $\mathrm{O}$ autor agradece também à Professora Maria Cecília Pereira a gentileza do auxílio na revisão do texto e a pertinência das observações.

\section{Referências}

ADLER, P. S.; WINOGRAD, T. A. Usability: turning technologies into tools. Oxford: Oxford University Press, Inc., 1992.

CARROL, C. et al. Involving users in the design and usability evaluation of a clinical decision support system. Computer Methods and Programs in Biomedicine, v. 69, n. 2, p.123-135, 2002. http://dx.doi.org/10.1016/ S0169-2607(02)00036-6

COSTA, S. F. Usabilidade no projeto de produto: um estudo de caso na área de transmissão de energia. 2006. Dissertação. (Mestrado em Engenharia de 
Produção)- Universidade Federal de Minas Gerais, UFMG, Belo Horizonte, 2006.

DE ARAÚJO, A. G.; CASÃO JUNIOR, R; DE FIGUEIREDO, P. R. A. Field evaluation of animal traction equipment for soil tillage in Brazil. Agricultural Mechanization in Asia, Africa and Latin America AMA, v. 30, n. 3, p. 23-27, 1999.

DREYFUSS, H. Design for people. New York: Allworth Press, 1955.

DREYFUSS, H.The measure of man and woman: human factors in design. New York: Dreyfuss Associates, 2001.

FERREIRA, D. M. P. (Coord.). Pesquisa antropométrica e biodinâmica dos operários da indústria de transformação - RJ. Rio de Janeiro: Instituto Nacional de Tecnologia, 1988. v. 1.

FREUND, J.; TAKALA, E-P; TOIVONEN, R. Effects of two ergonomic aids on the usability of an in-line screwdriver. Applied Ergonomics, v. 31, n.4, p. 371-376, 2000. http://dx.doi.org/10.1016/S0003-6870(00)00005-3

GARMER, K. et al. Application of usability testing to the development of medical equipment: usability testing of a frequently used infusion pump and a new user interface for an infusion pump developed with a human factors approach. International Journal of Industrial Ergonomics, v. 29, n. 3, p. 145-159, 2002. http://dx.doi. org/10.1016/S0169-8141(01)00060-9

GARMER, K.; YLVÉN, J. I. C.; KARLSSON, M. User participation in requirements elicitation comparing focus group interviews and usability tests for eliciting usability for medical equipment: a case study. International Journal of Industrial Ergonomics, v.33, n.2, p. 85-98, 2004. http://dx.doi.org/10.1016/j.ergon.2003.07.005

GUÉRIN, F. et al. Compreender o trabalho para transformá-lo: a prática da ergonomia. São Paulo: Edgard Blücher, 2001.

IIDA, I. Ergonomia: projeto e produção. 2. ed. São Paulo: Edgard Blücher, 2005.

INTERNATIONAL ORGANIZATION FOR STANDARTZATION - ISO. ISO/TR 13407: Humancentred design process for interactive systems. Genève: International Organization for Standartzation, 1999.

INTERNATIONAL ORGANIZATION FOR STANDARTZATION - ISO. ISO/TR 18529: Ergonomics of human-system interaction. Human-centred lifecycle process descriptions. Genève: International Organization for Standartzation, 2000.

JAFRY, T.; O'NEILL, D. H. The application of ergonomics in rural development: a review. Applied Ergonomics, v. 31, n. 3, p. 263-268, 2000. http://dx.doi.org/10.1016/ S0003-6870(99)00051-4

KOGI, K. Participatory methods effective for ergonomic workplace improvement. Applied Ergonomics, v. 37, n. 4, p. 547-554, 2006. PMid:16756940. http://dx.doi. org/10.1016/j.apergo.2006.04.013

KROEMER, K. H. E.; GRANDJEAN, E. Manual de ergonomia: adaptando o trabalho ao homem. 5. ed. Porto Alegre: Bookman, 2005.

LIU, Y; OSVALDER, A-L. Usability evaluation of a GUI prototype for a ventilator machine. Journal of
Clinical Monitoring and Computing, v. 18, n. 5-6, 2004. PMid:15957628. http://dx.doi.org/10.1007/ s10877-005-7997-9

NEMETH, C. P. Human factors methods for design: making systems human-centered. New York: CRC Press, 2004. http://dx.doi.org/10.1201/9780203643662

NIELSEN, J. Usability engineering. London: Academic Press, 1993.

ORTIZ-LAUREL, H.; RÖSSEL, D. Current status of animal traction in Mexico. Agricultural Mechanization in Asia, Africa and Latin America - AMA, v. 38, n. 1, p. 83-88, 2007.

PECHE FILHO, A. et al. Chassi porta implementos triangular: desenvolvimento e desempenho operacional. In: CONGRESSO BRASILEIRO DE ENGENHARIA AGRÍCOLA, 16.1987, Jundiaí. Anais... Jundiaí: Sociedade Brasileira de Engenharia Agrícola, 1987. p. 266-271, v. 1.

PRAHALAD, C. K. The Fortune at the Bottom of the Pyramid. New York: Wharton School Publishing, 2009. Revised and Updated 5th Anniversary Edition: Eradicating Poverty Through Profits.

RAMASWAMY, N. Draught animals and welfare. Revue Scientifique et Technique (International Office of Epizootics), v. 13, p. 195-216, 1994.

ROMANO, L. N. et al. An introduction to the reference model for the agricultural machinery development process. Product: Management \& Development, v. 3, n. 2, p. 109-132, 2005

ROSE, A. F. et al.Using qualitative studies to improve the usability of an EMR. Journal of Biomedical Informatics, v.38, n. 1, p. 51-60, 2005. PMid:15694885. http://dx.doi.org/10.1016/j.jbi.2004.11.006

RUBIN, J. Handbook of usability testing: how to plan, design and conduct effective tests. New York: John Wiley \& Sons, Inc., 1994, p.11

SANTOS, V. A abordagem ergonômica da utilização da tração animal em pequenas explorações agrícolas brasileiras. Paris: Conservatoire National des Arts e Métiers, 1986. Pesquisa para Doutorado.

SHAHNAVAZ, H. Transfer of technology to industrial developing countries and human factors considerations. Lulea University (Sweden), Center for Ergonomics of Developing Countries, 1991.

SHINNO, H. et al. Product development methodology for machine tools. Tokyo: Japanese Society of Mechanical Engineering, 2002.

WILSON, R. T. The environmental ecology of oxen used for draught power. Agriculture, Ecosystems \& Environment, v. 97, n. 1-3, p. 21-37, 2003. http:// dx.doi.org/10.1016/S0167-8809(03)00118-X

WISNER, A. Consecuencias de la transferência de tecnicas sobre as condiciones de trabajo. Paris: CNAN, 1985.

WISNER, A. Por dentro do trabalho - ergonomia: método \& técnica. São Paulo: FTD/Oboré, 1987.

WISNER, A. A fábrica do futuro nos países de industrialização recente: transferência de tecnologia ou reconcepção global? Rio de Janeiro: COPPE/UFRJ, 1991. Texto de palestra. 